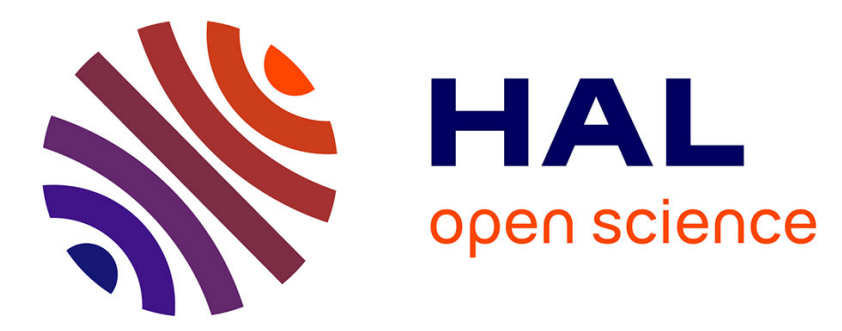

\title{
Rupture of an Evaporating Liquid Bridge between Two Grains
}

\author{
Boleslaw Mielniczuk, Moulay Saïd El Youssoufi, Laurent Sabatier, Tomasz
}

Hueckel

\section{- To cite this version:}

Boleslaw Mielniczuk, Moulay Saïd El Youssoufi, Laurent Sabatier, Tomasz Hueckel. Rupture of an Evaporating Liquid Bridge between Two Grains. Acta Geophysica, 2014, 62 (5), pp.1087-1108. 10.2478/s11600-014-0225-6 . hal-01141503

\section{HAL Id: hal-01141503 \\ https://hal.science/hal-01141503}

Submitted on 13 Apr 2015

HAL is a multi-disciplinary open access archive for the deposit and dissemination of scientific research documents, whether they are published or not. The documents may come from teaching and research institutions in France or abroad, or from public or private research centers.
L'archive ouverte pluridisciplinaire HAL, est destinée au dépôt et à la diffusion de documents scientifiques de niveau recherche, publiés ou non, émanant des établissements d'enseignement et de recherche français ou étrangers, des laboratoires publics ou privés. 


\title{
Rupture of an Evaporating Liquid Bridge between Two Grains
}

\author{
Boleslaw MIELNICZUK ${ }^{1,2}$, Moulay Said EL YOUSSOUFI ${ }^{2,3}$, \\ Laurent SABATIER ${ }^{2,3}$, and Tomasz HUECKEL ${ }^{4}$ \\ ${ }^{1}$ Institut de Radioprotection et de Sûreté Nucléaire (IRSN), \\ Saint-Paul-lez-Durance, France \\ ${ }^{2}$ Laboratoire de Micromécanique et d'Intégrité des Structures, \\ MIST, IRSN-CNRS-Université de Montpellier 2, Montpellier, France \\ e-mails: boleslaw.mielniczuk@univ-montp2.fr, \\ Moulay-Said.El-Youssoufi@univ-montp2.fr, laurent.sabatier@univ-montp2.fr \\ ${ }^{3}$ LMGC UMR CNRS, Université de Montpellier 2, Montpellier, France \\ ${ }^{4}$ Duke University, Durham, NC, USA; e-mail: hueckel@duke.edu
}

\begin{abstract}
The study examines rupture of evaporating liquid bridges between two glass spheres. Evolution of the bridge profile has been recorded with the use of high-speed camera. Geometrical characteristics of the bridge were then used to calculate evolution of the variables during the process: Laplace pressure, capillary force, and surface tension force. For the purpose of reference, the bridge evolution is followed also during kinematic extension. During both processes the diameter of the neck decreases, with an acceleration of about 1-2 ms before the rupture. Two distinct rupture modes are observed, depending on the bridge aspect ratio. After the rupture, the mass of liquid splits, forming two separate oscillating drops attached to the spheres, and a suspended satellite droplet. Just before the rupture, an increasing repulsive Laplace pressure, and decreasing negative surface tension force develop. Capillary force follows the trend of the surface tension force, with an accelerating decline. Duration of the whole process and liquid mass stabilization is from 10 to $60 \mathrm{~ms}$.
\end{abstract}

Key words: capillary bridge, evaporation, rupture, capillary force. 


\section{INTRODUCTION}

Evolution of capillary bridges between solid surfaces and their rupture due to evaporation is of relevance in a number of technologies. In the geophysics and geoengineering context, evaporation affects capillary forces, which are believed to generate an apparent cohesion of unsaturated soils in field conditions. Rupture of capillary bridges is a precursor of drying-cracking affecting negatively the stability of slopes, dikes, levees, etc. (see, e.g., Hoek and Bray 1981, Bièvre et al. 2012). Exposure to evaporation of the free surface of soil hydraulic barriers, including those in nuclear waste technology, leads to drying cracks, with worrying consequences to the hydraulic conductivity (Dixon et al. 2002, Peron et al. 2009a, b).

Liquid bridges between grains have significant influence on mechanical properties of granular media, due to intergranular forces causing an increase of cohesion and mechanical strength of such materials. However, in a series of environments, the liquid of the bridge tends to evaporate, which leads to its gradual mass/volume reduction to zero and substantial evolution of its shape and, consequently, Laplace pressure (suction) and capillary forces. In some circumstances the bridges undergo rupture, while still containing a substantial fraction of its original water volume. At a scale of an evaporating granular medium, decreasing moisture content leads to the material shrinkage, which in the presence of kinematic constraints or gradients of moisture, induces stress. At certain tensile stress conditions, the material may crack. Cracking of the material is observed at the moment coincident with the formation and rupture of liquid bridges, when air entries into the body of the porous material (Hu et al. 2007, 2011, 2013a, b, Kowalski and Mielniczuk 2007, Peron et al. 2009a, b, 2013, Hueckel et al. 2014). Also other phenomena, such as suction hardening and softening (wetting collapse), are related to the evolution and rupture of liquid bridges (Gili and Alonso 2002). Previous studies at a micro scale revealed that rupture of a liquid bridge is coincident with a sudden decrease of intergranular forces (Hueckel et al. 2013).

In this study, rupture of elementary pendular liquid bridges between two particles during natural convective evaporation is examined. To provide a broader context, the evaporation test results are compared to those obtained at rupture during extension tests of capillary bridges. The bifurcation and rupture of the liquid bridges during evaporation have not been systematically investigated earlier.

\section{EXPERIMENTAL}

Rupture of liquid bridges between two spheres has been examined during evaporation of a liquid volume of initially $4 \mu$, at different values of separation $D$, from 0.1 to $2.0 \mathrm{~mm}$. The liquid with surface tension of $0.05 \mathrm{~N} / \mathrm{m}$ is 
distilled water with $8.5 \%$ of ethanol by volume used as a standard fluid in LMGC Lab, Montpellier (Gras et al. 2013). The ethanol comes from standardized procedure of cleaning the glass beads. The auxiliary tests of extension of the bridge, with a pre-determined volume from 0.1 to $10 \mu 1$ were also conducted for comparison. The rate of change in separation was $16 \mu \mathrm{m} / \mathrm{s}$. Both types of experiments were carried on in the vertical and horizontal configurations, with the use of precision borosilicate spheres, $8 \mathrm{~mm}$ in diameter. Several tests were made also for different sphere diameters $(3.5$ and $9 \mathrm{~mm})$, showing no appreciable qualitative differences. To image the moment of rupture, a high-speed digital camera (Vision Research Phantom v. 12) was used, with the frame rate of more than 27000 frames per second. The camera was continuously recording the whole process. The images of the moment of rupture were identified using a trigger just after the rupture, and then the chosen portion of the recorded movie was saved on a PC. Each sequence included the bridge evolution before rupture, the rupture proper, and stabilization of the remnant liquid bodies. Obtained sequences were processed with ImageJ, MBRuler Pro, and Mathlab programs, to determine geometrical parameters as follows: (i) radius of curvature of the surface of the liquid body measured at the equator $r_{\mathrm{g}}$ ("neck" or gorge radius); (ii) radius of the external curvature of the meniscus along a "meridian" of the bridge surface, $r_{\text {ext }}$; (iii) water wire parameters $\left(l_{\mathrm{w}}, r_{\mathrm{w}}\right)$; (iv) satellite droplet radius $r_{\mathrm{dr}}$; and (v) parameters of liquid drops after rupture (Fig. 1).

The measurements made it possible to calculate (under some assumptions): (i) Laplace pressure $\Delta p$ and the corresponding resultant force component $F_{\Delta p}$ of the interparticle force; (ii) surface tension component of the interparticle force $F_{\mathrm{ST}}$; (iii) total capillary force $F_{\mathrm{CAP}}$; (iv) liquid volume, $V$ at the moment of rupture (calculated based on images after rupture); (v) frequency of oscillations of post-rupture water bodies; (vi) axial stress; and other variables.

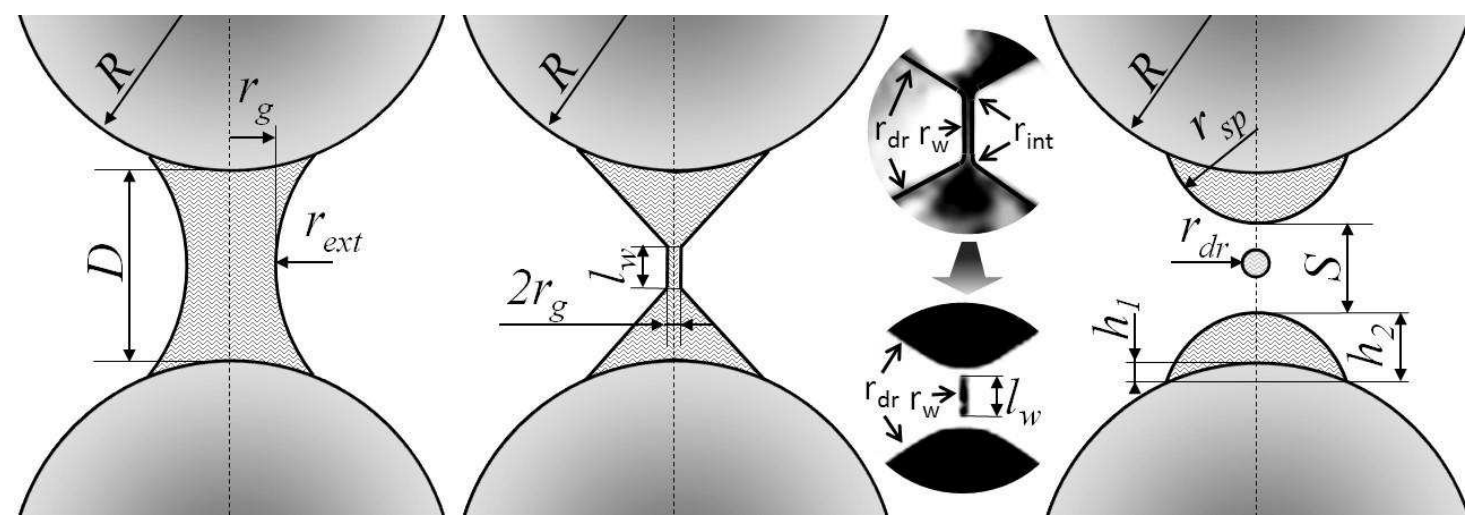

Fig. 1. Outline of the capillary bridge between two spheres at different moments of rupture: thinning bridge, creation of water wire, rupture, and after rupture. 
Each of the tests has been repeated several times, with certain scatter, usually corresponding to a non-symmetric initial shape of the bridge, most likely due to the manual water placement procedure (errors up to $10 \%$ ).

\section{RESULTS}

The record of the entire process of evaporation of capillary bridges, including the pre-rupture evolution of the bridge shape and its geometrical characteristics, as well as the measured and calculated capillary forces is presented in a separate paper (Mielniczuk et al. 2014). In this study we examine the very instant of rupture of liquid bridges caused by its evaporation. The rupture during extension of the liquid bridges has been tested for the purpose of comparison.

The identification of the onset of rupture is not an obvious task, as per se rupture is a phase in the evolution of the bridge during drying. However, what causes rapture during drying, and what is the dynamics of its development, and what could be possible outcomes, are open questions. Without making any judgment on the precursors of rupture, there are two ways in which onset of rupture can be defined: (a) as an onset of irreversibility - by performing an attempt to reverse the process via inducing a condensation or adding a limited amount of liquid, or (b) as an onset of instability - by identifying a point at which a change of any of geometrical characteristics of the bridge significantly accelerates.

It appears that rupture of the capillary bridge in itself develops during evaporation in two distinct modes depending on the separation of the spheres, or in other terms, given that all bridges have the same initial liquid volume, on the bridge initial aspect ratio. The first one, called henceforth Mode 1, occurs at higher separations, or high aspect ratio, that is, for tall and slim bridges, consists in a relatively early transition from a classical curvilinear bridge shape into a straight water wire (Fig. 1). The wire has distinctly different geometrical characteristics from the initial bridge. The wire then ruptures in a short period of time.

Mode 2 develops at smaller separations, and hence at smaller aspect ratios of the bridge, that is, in short and wide bridges, with a much reduced volume at rupture. In Mode 2 water-wires are not observed at all. Instead, the central part of the bridge becomes longer and thinner with time, but still with a visible external curvature. Eventually the bridge breaks in the middle. The high rate of rupture suggests that it is a mechanical phenomenon, rather than one resulting from the mass loss, which is much slower.

Table 1 shows the timing and evaporation progress characteristics at the instant of the instability, as seen on a time macro-scale (minutes).

It is realized from Table 1 that for substantial separations, in Mode 1 the rupture can start very early, with about $75 \%$ of water remaining in a liquid 
Table 1

Main characteristics of rupture for evaporating liquid bridges

\begin{tabular}{|c|c|c|c|c|c|}
\hline Grain separation, $D[\mathrm{~mm}]$ & 2 & 1.3 & 0.7 & 0.4 & 0.1 \\
\hline Time to rupture [min] & 9 & 22 & 46 & 53 & 67 \\
\hline Relative separation, $D^{*}=D / R$ & 0.5 & 0.266 & 0.176 & 0.1 & 0.026 \\
\hline Liquid volume at rupture, $D_{\text {rup }}[\mu 1]$ & 3.09 & 2.28 & 0.89 & 0.31 & 0.16 \\
\hline Relative volume loss at rupture $^{1}$ & 0.227 & 0.43 & 0.777 & 0.92 & 0.959 \\
\hline Rupture mode & \multicolumn{2}{|c|}{ Mode I } & \multicolumn{3}{|c|}{ Mode II } \\
\hline
\end{tabular}

${ }^{1)}$ The relative volume loss is defined as a ratio of the volume of the evaporated liquid to its original volume.

state. The initial stage of the process with a continuously evolving bridge shape lasts between 9 and 20 minutes. The rate of change of basic geometrical parameters is practically equal to the rate of evaporation. The first stage of rupture consists of formation of the liquid wire, which occurs on a microtime scale of milliseconds, i.e., at a much higher rate. Hence it is not driven by evaporation, but rather by a presumed mechanical instability. It takes from 0.2 to $0.4 \mathrm{~ms}$. However, there is a precursor to this occurrence in terms of a change in the rate of the radius evolution, starting 1 to $2 \mathrm{~ms}$ prior to the water-wire formation. In the second stage of Mode 1, the water-wire is pinched at two locations simultaneously (at the junction with the conical mass of water between the water-wire and the spheres) in a time period less than $1 \mathrm{~ms}$.

Figure 2 presents all phases of Mode 1 rupture of the liquid bridge between two spheres, during its evaporation. Both vertical and horizontal configurations are shown for optimal visualization. A clear difference between the shape of the bridge can be seen between the shape of the mid-section of the initial clepsydra-shaped bridge with a clear curvature and what it evolves into which is an almost cylindrical columnar bridge of practically zero external curvature. The water-wire is spanned between two conical drops adhering to the glass spheres (Fig. 2, $0 \mathrm{~ms}$ ). This stage of rupture bears strong analogy to Plateau's (1873) failure mode, which he observed in liquid jets and which are reproduced in Fig. 2c; see also Bush (2004).

In the successive stage, the water-wire at nearly constant diameter extends its length at the expense of the height of the conical liquid bodies near the grains to eventually be pinched off at the two ends simultaneously (Fig. 2, $0.11 \mathrm{~ms}$ ). This final stage, from the appearance of cylindrical shape to the rupture, lasts about $0.1 \mathrm{~ms}$. This rupture bears strong similarity to pinch-off instability (Bernoff et al. 1998, Leppinen and Lister 2003), which 
a)
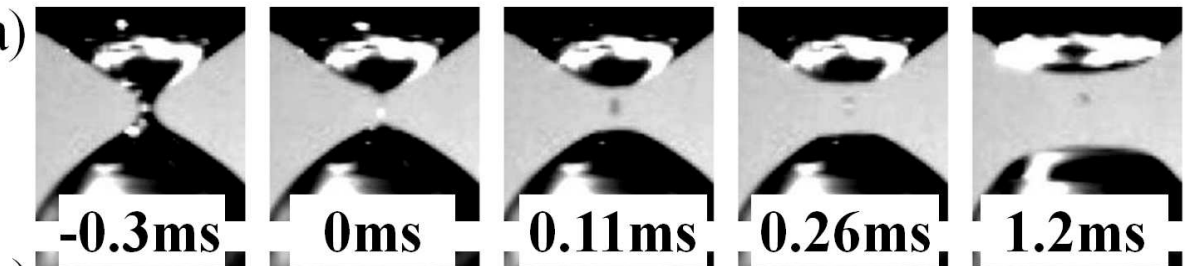

b)
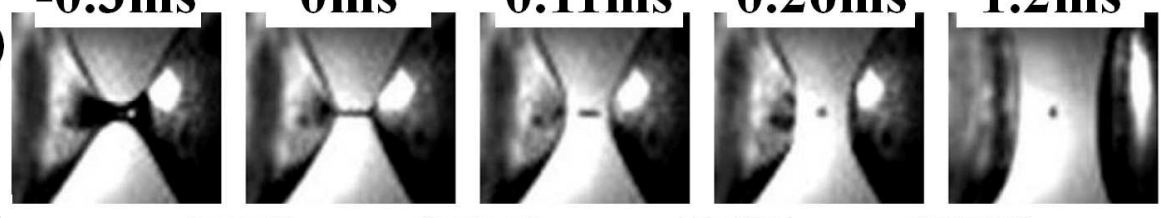

c)
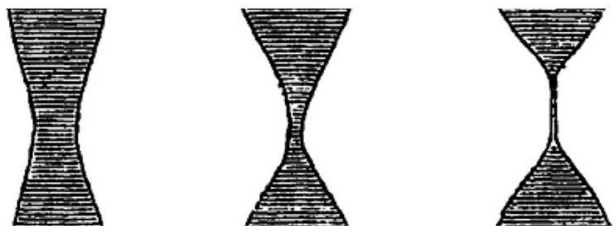

要

-

○

$\cdot$

Fig. 2. Rupture of evaporating capillary bridge between two spheres in: (a) vertical configuration (separation $2000 \mu \mathrm{m}$, spheres $8 \mathrm{~mm}$ ), and (b) horizontal configuration (separation $1400 \mu \mathrm{m}$, spheres of $9 \mathrm{~mm}$ ). Subsequent stages of rupture are visible: necking of the bridge, creation of water wire, rupture (at two points), satellite droplet, and drops oscillations. (c) Failure mode observed in water jets by Plateau (1873).

is observed in flowing water bodies. Immediately after rupture, the hanging water-wire persists over some milliseconds in its cylindrical form and eventually transforms into a spherical satellite drop, presumably to minimize the surface energy. The entire system of all involved liquid bodies suffers recoil pulsations for 2-3 ms. The satellite drop stays in its central position for quite some time (compared to the rupture time period) and subsequently falls down due to the gravity (Fig. $2 b, 0.26-1.2 \mathrm{~ms}$ ). In several tests in the vertical configuration the droplet moved upward (Fig. 2a, 0.26-1.2 ms) and then has been adsorbed by the upper water hemisphere.

As an outcome of rupture, the liquid mass splits, forming two large, independently evolving hemispherical or tapered drops, attached to the glass spheres (Fig. 2, 0.11-1.2 ms). The release of the intergranular forces at the moment of rupture generates an oscillatory deformation of these drops with an average frequency dependent on liquid volume and separation until a new stable configuration is reached. The oscillations of the liquid cones are much slower than the oscillations of the satellite droplet, presumably because of their much higher mass.

For Mode 2 (in short and large bridges) the water-wires are not observed. The central part of the bridge becomes longer and thinner with time, and the bridge eventually breaks in the middle. The current liquid volume at rupture is much smaller than for Mode 1 rupture. Two parts of the split water bridge are subsequently "attracted" by the two grains, creating two hemispherical droplets, oscillating during several milliseconds. Such a behavior was ob- 
served in the evaporating bridges at separations of $1300 \mu \mathrm{m}$ (volume at rupture of $2.28 \mu \mathrm{l}$ ) and lower, and in the extended bridges with the volume of $2 \mu l$ and lower, for both horizontal and vertical configurations.

During evaporation, the relative volume loss and geometric characteristics at the moment of rupture depend on the separation of the spheres. The volume at rupture ranges between $3.09 \mu$, corresponding to 0.227 of the relative volume loss, at the largest separation $(2 \mathrm{~mm})$, and $0.16 \mu 1(0.959$ of the relative volume loss), at very small separations (Fig. 4 , see also Hueckel et al. 2013). Hence, it is concluded that for larger separations, i.e., for tall bridges, the bridge failure interrupts a smooth drying process quite early, whilst for very small separations, i.e., short and wide bridges, rupture of the liquid bridge practically blends with the vanishing of all liquid mass via evaporation.

The modes of rupture developing during extension of liquid bridges are in general quite similar to those seen during evaporation. Mode 1, with the water-wire, is likely to form at higher volumes of liquid ( $4 \mu 1$ and over), whereas for the bridge volumes lower than $2 \mu 1$ the bridge ruptures in the middle without formation of a cylindrical water column (Mode 2). Interestingly, two versions of Mode 1 are seen. They differ in how rupture of waterwire occurs. At the volumes of 4 and $6 \mu$, water-wire breaks at both endpoints simultaneously, like during evaporation in what we will call Mode 1a. This event creates first a hanging water stick, subsequently evolving into a spherical satellite droplet hanging between two, now separated parts of the water body, to eventually fall in the gravity field. At volumes over $6 \mu$, water-wire breaks (Mode 1b) first at a lower extremity, and after, in about $0.02 \mathrm{~ms}$, at the upper extremity. It then transforms into the satellite droplet, which later moves upwards, probably propelled by the momentum of the henceforth un-balanced capillary force just after the rupture at the lower extremity. Figure 3 shows a sequence of images of the evolution of the water bridge during an extension tests shortly before the rupture.
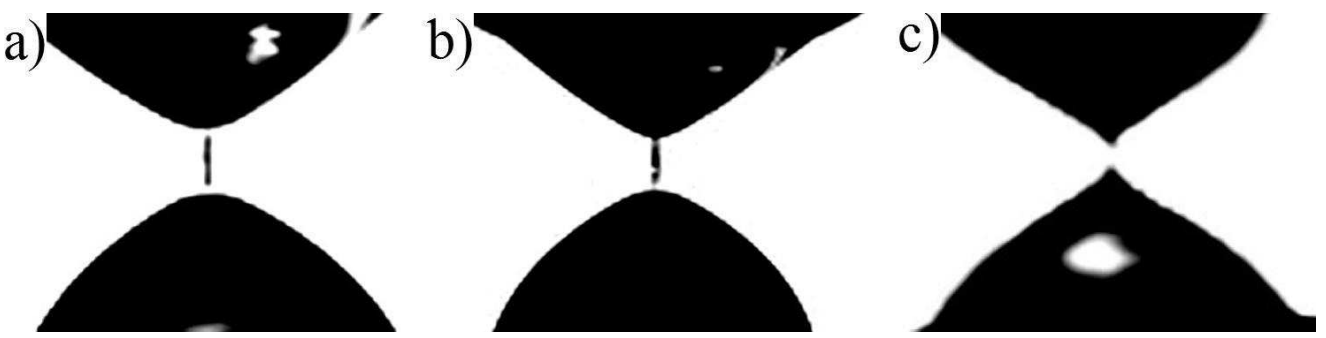

Fig. 3. Evolution of the liquid bridge between two spheres during extension, with constant water volume: (a) Mode 1a (symmetric, two pinchings, volume $4 \mu 1$ ), (b) Mode $1 \mathrm{~b}$ (non-symmetric, one pinching, volume $8 \mu \mathrm{l}$ ), and (c) Mode 2 ( rupture in the middle, volume $2 \mu 1$ ). 
Table 2

Main parameters of rupture for liquid bridges during extension

\begin{tabular}{|l|c|c|c|c|c|c|}
\hline Liquid volume, $V[\mu 1]$ & 1 & 2 & 4 & 6 & 8 & 10 \\
\hline Time at rupture $[\mathrm{s}]$ & 95 & 105 & 135 & 140 & 150 & 155 \\
\hline Separation at rupture, $D_{\text {rup }}[\mathrm{mm}]$ & 0.78 & 1.54 & 2.02 & 2.23 & 2.46 & 2.62 \\
\hline $\begin{array}{l}\text { Relative separation at rupture, } \\
D_{\text {rup }}=D_{\text {rup }} / R\end{array}$ & 0.20 & 0.38 & 0.5 & 0.56 & 0.62 & 0.66 \\
\hline
\end{tabular}

Table 2 shows time and separation at the instant of onset of rupture and relative separation at rupture. Clearly, time to rupture in the case of extension tests is dependent on the chosen extension rate, and is anyway much shorter than in the evaporation case.

In the studies on extension of liquid bridges at constant liquid volume it is often postulated that there is a one-to-one relationship between separation at rupture and the gorge radius (Mason and Clark 1965, Erle et al. 1971) or relative separation at rupture and the pre-established constant liquid volume (Lian et al. 1993, Willett et al. 2000). The principle behind that type of postulates is that Young-Laplace equation relating the capillary pressure to the mean curvature of the liquid body has two solutions, converging to one solution at a specific separation of the grains (Lian et al. 1993). According to the postulate of Erle et al. (1971), there is no transition between the solutions, and the point of convergence corresponds to the rupture point. An alternative proposition of De Bisschop and Rigole (1982) is that rupture corresponds to a minimum of a half-filling angle (see also Mazzone et al. 1986). In that context we have set up in Fig. 4 the experimental values of the separation versus liquid bridge volume at rupture for evaporation and extension experiments. These results are compared with the values of separation at rupture predicted by an empirical formula proposed by Lian et al. (1993) based on their tests with the liquid bridges during extension. Contact angles, which are required in the Lian et al. (1993) formula, were determined from the experiments just before the rupture, as a mean value of four visible contact angles, for several different tests, in horizontal and vertical configuration, with the resulting values of $\theta_{\operatorname{mean} H}=29.3^{\circ}$ for horizontal, and $\theta_{\text {mean } V}=$ $24.5^{\circ}$ for vertical configuration, respectively. As one can observe, the experimentally measured separations at rupture for vertical extension tests are in good agreement with the Lian et al. (1993) prediction. This agreement we see as a confirmation of the suitability of our experimental techniques to investigate rupture during evaporation, for which there is no analogous empirical formulae available. 


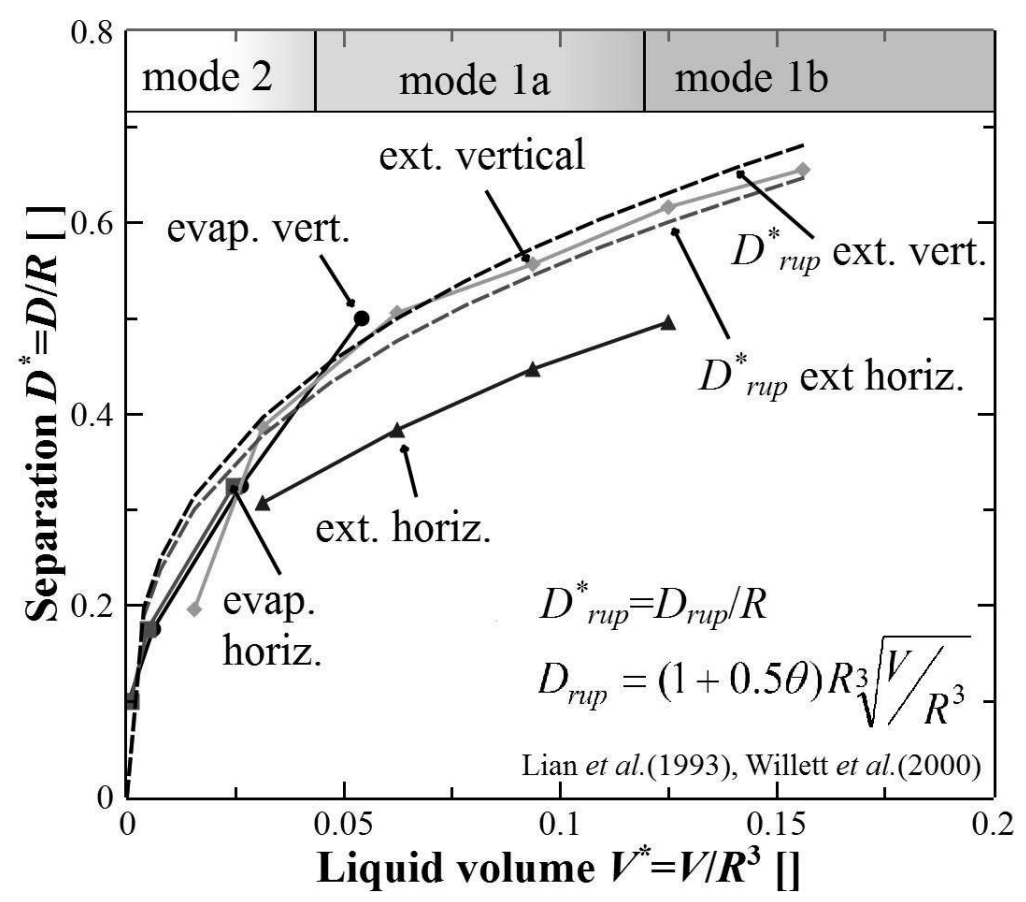

Fig. 4. Relation between relative separations at rupture $D_{\text {rup }}$ and the normalized volume at rupture $V_{\text {rup }}$ for evaporation and extension tests, compared with the calculated separation at rupture as proposed by Lian et al. (1993) and Willett et al. (2000), dashed lines. The ranges of the three main modes of rupture observed during investigations are indicated. Colour version of this figure is available in electronic edition only.

The separations at rupture and corresponding volumes for horizontal tests follow a separate trend, with noticeably smaller separations for horizontal setups.

Rupture of a liquid bridge and conditions for its occurrence may be viewed as an outcome of its prior evolution. The latter may be quantitatively characterized based on the measured geometrical parameters of the bridge, in particular the curvature radius of the neck (gorge radius, $r_{g}$ ) and the curvature radius of the external bridge profile (external radius, $\left.r_{\text {ext }}\right)$. The radii are also represented as normalized with respect to grain separation, hence $r_{g}{ }^{*}=$ $r_{g} / D$ and $r_{\mathrm{ext}}{ }^{*}=r_{\mathrm{ext}} / D$. These two variables determine the mean curvature of liquid bridge, and according to Young-Laplace law, the Laplace pressure and hence the intergranular forces.

The evolution of the both radii of curvature observed several milliseconds before the rupture is consistent with their evolution on the time macroscale (in minutes), described separately (in preparation). On time microscale, gorge radius, $r_{g}$, decreases linearly in time, but with a sudden acceleration about 1-2 ms before the rupture. The final value of $r_{g}$ is about 0.03 to $0.08 \mathrm{~mm}\left(r_{g}{ }^{*}\right.$ from 0.075 to 0.02$)$, for all tests, both of evaporation and extension. 

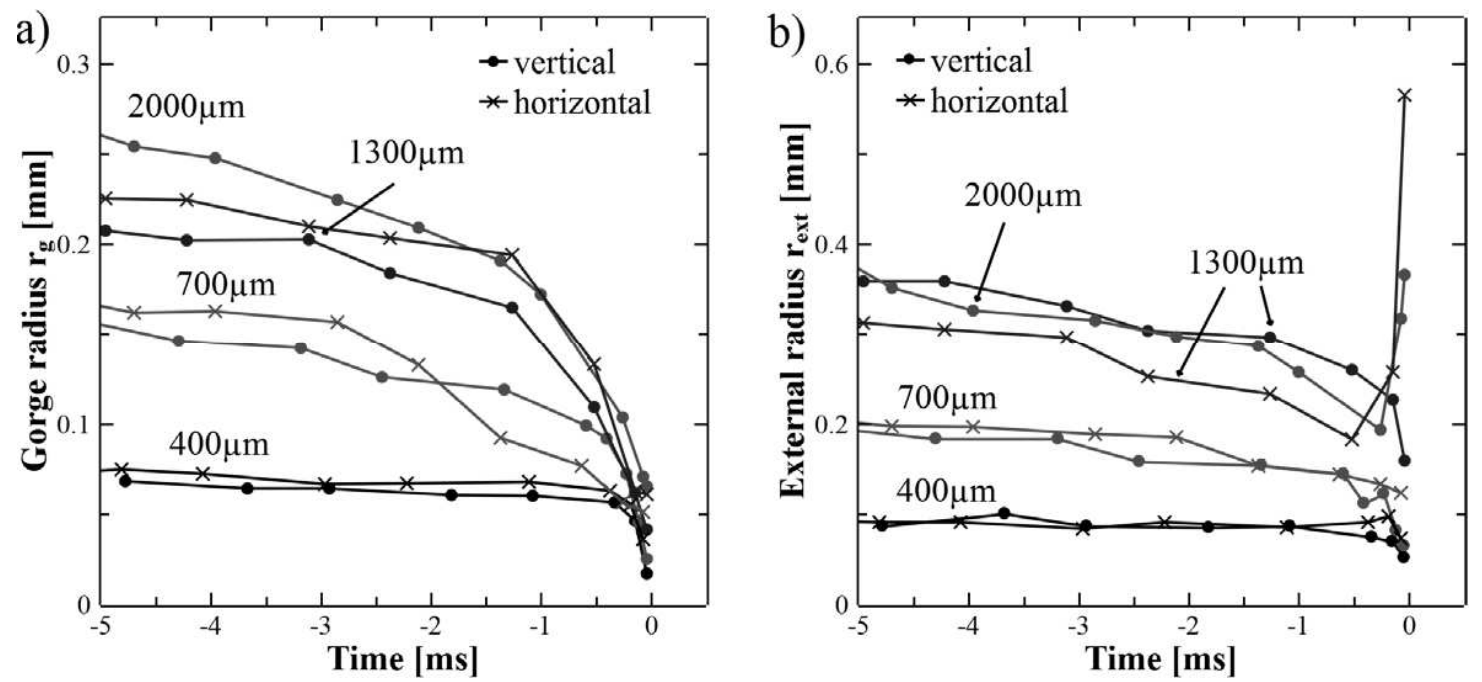

Fig. 5. Evolution of the radii of curvature at the gorge and external measured on the time micro-scale over $5 \mathrm{~ms}$ before the rupture during evaporation. Colour version of this figure is available in electronic edition only.

The external radius $r_{\text {ext }}$ decreases slightly from its initial values during evaporation (initial $r_{\mathrm{ext}}=0.1$ to $0.35 \mathrm{~mm}$, depending on separation, initial $r_{\mathrm{ext}}{ }^{*}=r_{\mathrm{ext}} / D$ is from 0.02 to 0.0875 ), and it is almost the same for all extension tests. At the moment of creation of the water-wire, the external radii, measured at the neck level, increase significantly, as the bridge in the central part becomes a long straight cylinder just before rupture.

The originally tallest and skinniest of the bridges are the thickest at the moment of rupture during evaporation, while during extension all bridges start at zero height and those first to rupture are the shortest and skinniest, and last is the tallest and thickest (Figs. 5 and 6). Also created water-wire is usually longer and thinner for extension tests, while during evaporation it becomes short and thick (Fig. 6).

Based on both radii of curvature it is possible to calculate Laplace pressure $\Delta p$, which is the difference of the liquid pressure inside the bridge and the ambient pressure (of gas). This Laplace pressure results from YoungLaplace law as proportional to the mean meniscus curvature $\Delta p=\gamma /\left(r_{g}{ }^{-1}-\right.$ $r_{\text {ext }}{ }^{-1}$ ), where $\gamma=0.05 \mathrm{~N} / \mathrm{m}$ is an experimentally determined surface tension coefficient for water with $8 \%$ of ethanol, as used in experiments (Hueckel et al. 2013, Gras et al. 2013). Results of calculation of the Laplace pressure for the last $5 \mathrm{~ms}$ prior to rupture in the evaporation tests are shown in Fig. 7.

Interestingly, while the Laplace pressure during most of the pre-rupture processes of evaporation and of extension is negative (suction) in high aspect ratio bridges, i.e., at high separations (see Fig. 8, reprinted from Mielniczuk et al. 2014), during the final stages, prior to rupture in Mode 1, the average value of pressure difference $\Delta p$ evolves into positive values. It happens most 

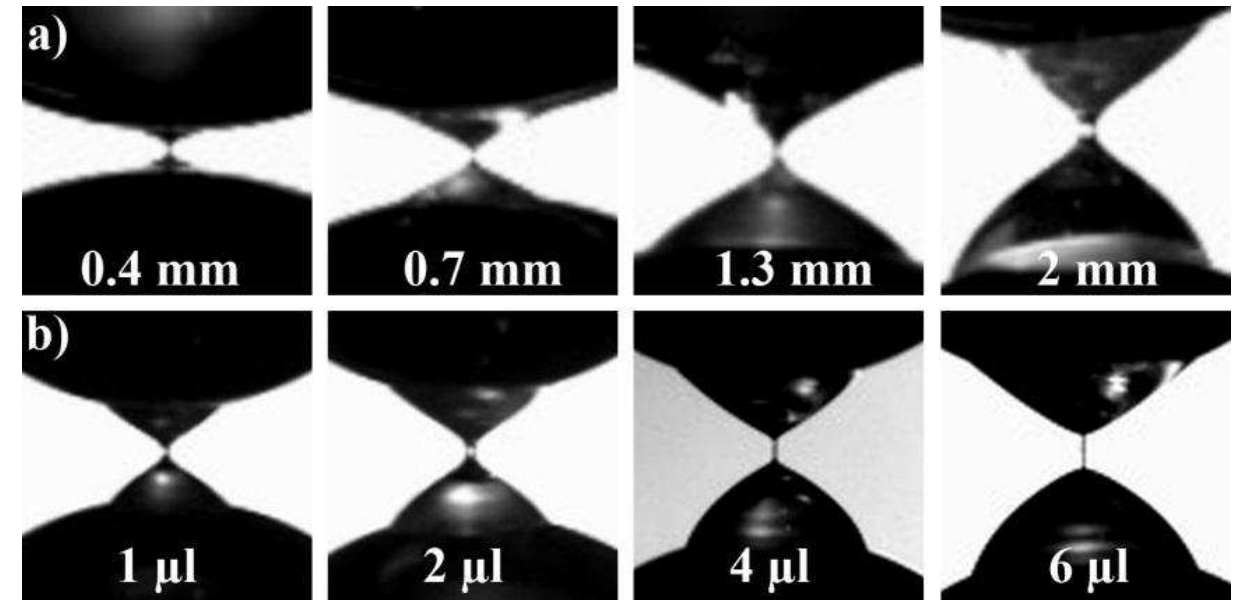

Fig. 6. The moment shortly before the rupture for evaporation at different separations (a) and extension tests at different liquid volumes (b).
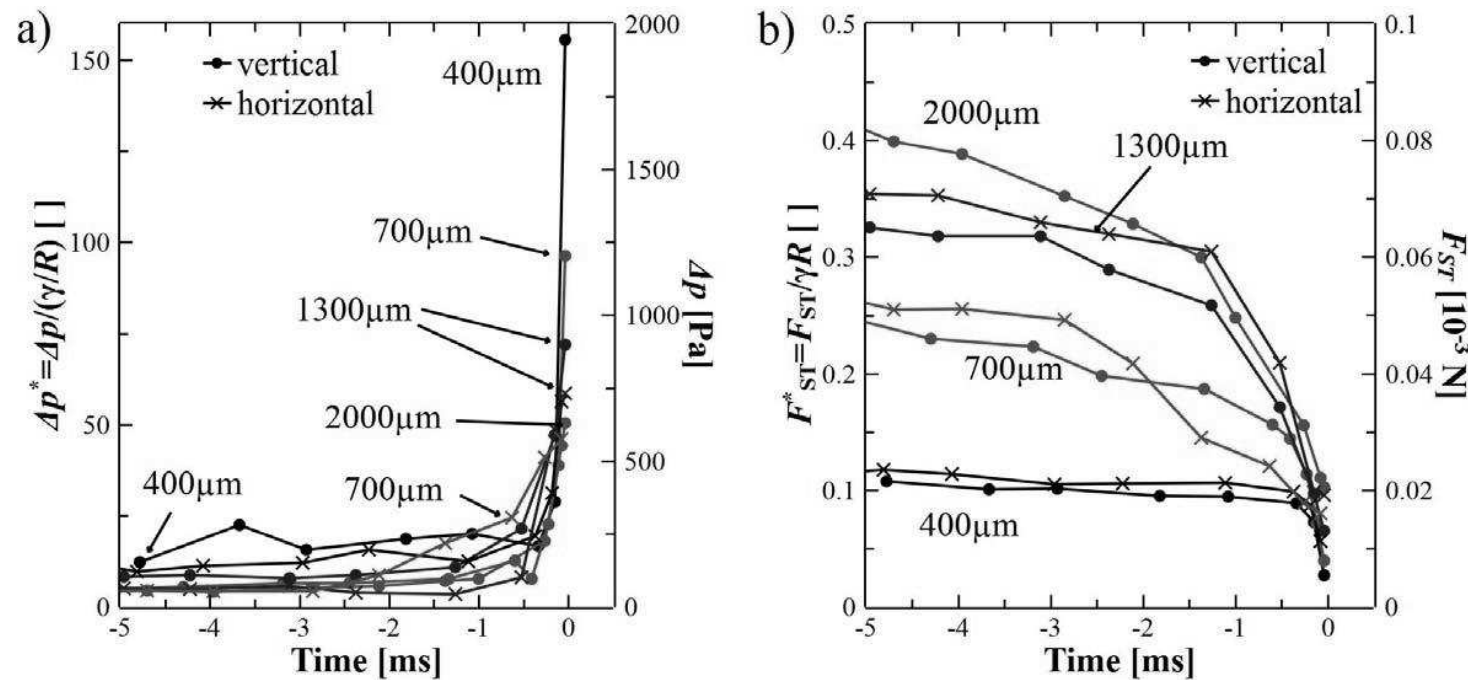

Fig. 7. Normalized and direct Laplace pressure evolution (a) and surface tension force evolution (b) before the rupture of evaporating capillary bridge in horizontal and vertical configurations as calculated from the experimental data of radii of curvature and experimentally determined surface tension. Colour version of this figure is available in electronic edition only.

likely due to a very small external curvature of the water-wire for both processes (for evaporation - Fig. 7a). Most characteristically, in Fig. 9 the data from time-micro-scale measurements are superposed on data from time macro-scale-scale showing that within last minute there is a positive Laplace pressure change over an order of magnitude.

The terminal $\Delta p$ values are from 500 to $1900 \mathrm{~Pa}\left(\Delta p^{*}=\Delta p R / \gamma\right.$ from 40 to 120), depending on the separation and the current volume of water.

Indeed, the final evolution stages prior to rupture in Mode 1 are characterized by quite a characteristic distribution of Laplace pressure across the 

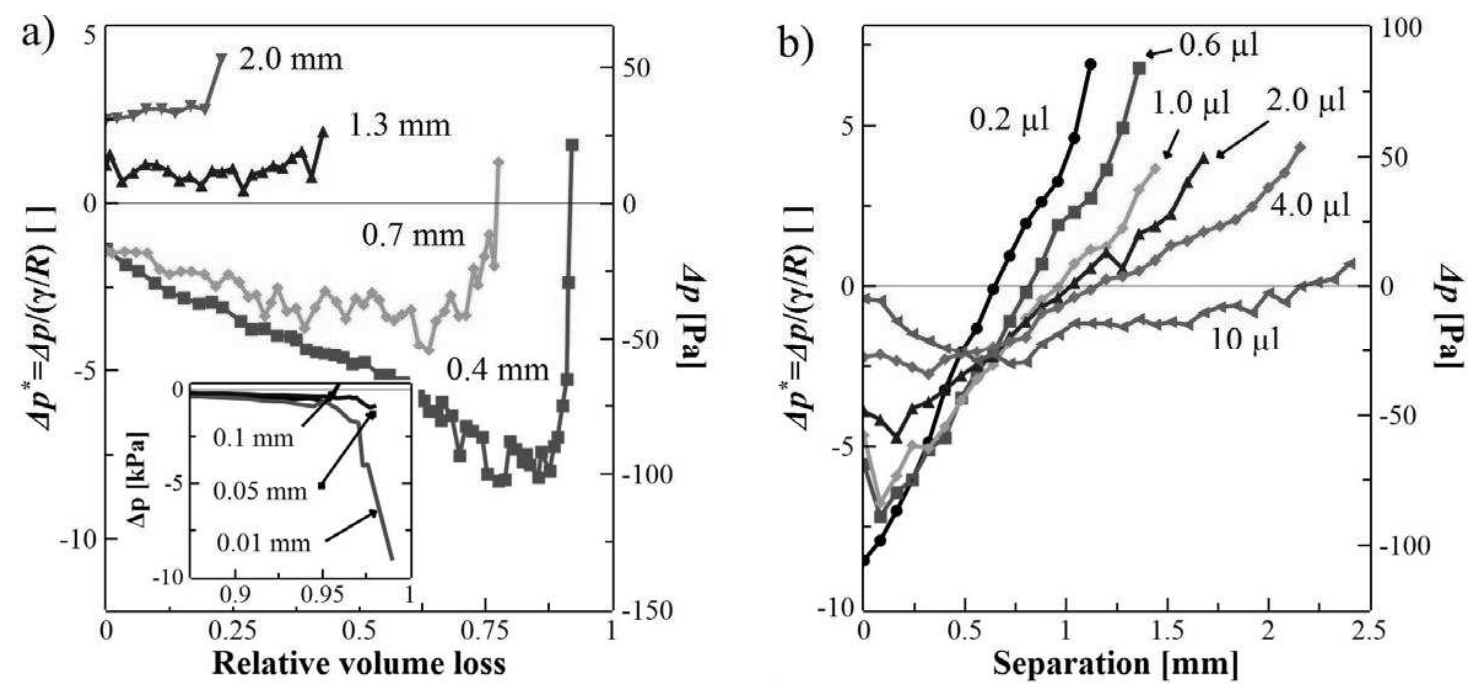

Fig. 8. Evolution of Laplace pressure during the entire process over a time macroscale (the measurement points were taken at every minute intervals) versus the variable: (a) relative volume loss during evaporation; and (b) separation in extension tests - reproduced from Mielniczuk et al. (2014). Colour version of this figure is available in electronic edition only.
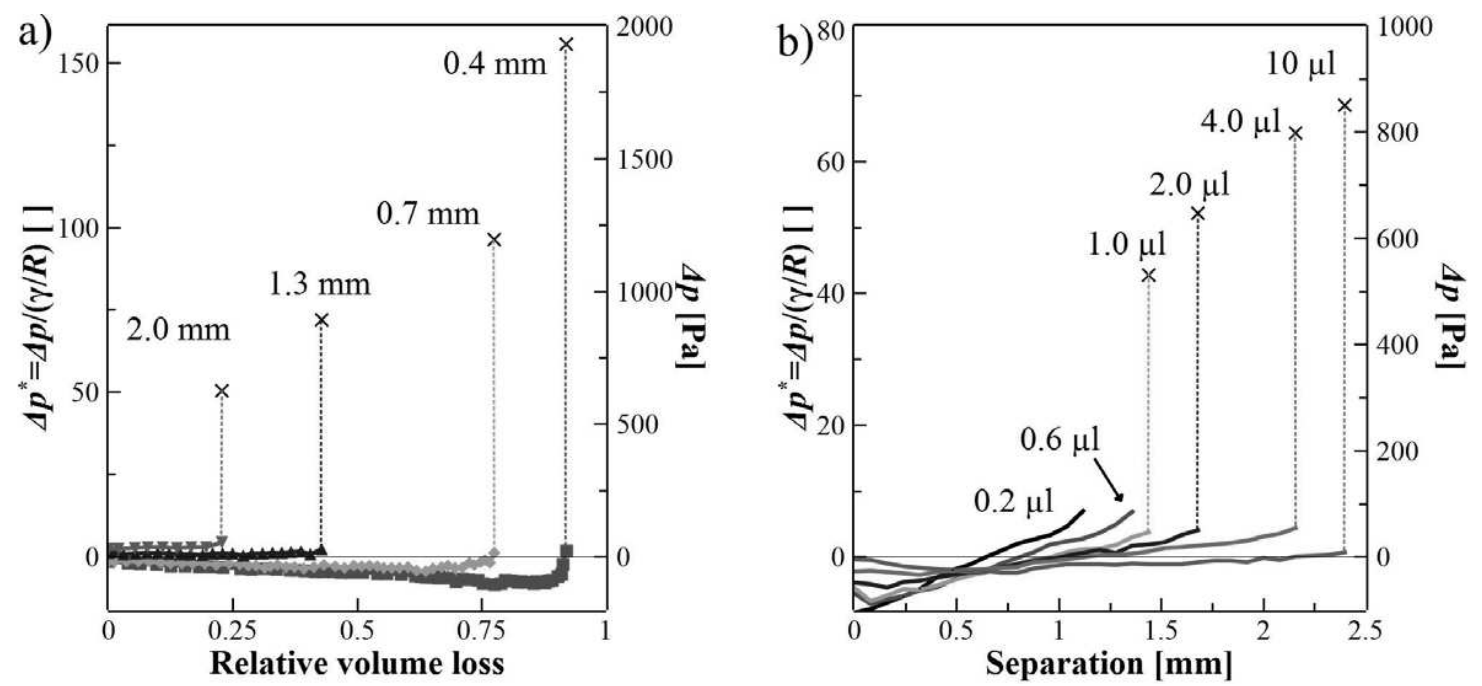

Fig. 9. Data from time micro-scale (Fig. 7) and from time macro-scale (Fig. 8) blended together. The dashed line and terminal points correspond to the data retrieved at the time micro-scale. Colour version of this figure is available in electronic edition only.

bridge. The formation of the water-wire induces in it a positive Laplace pressure, as the external curvature over its entire height is zero, while the curvature of the convex and thinning gorge is clearly positive and increasing. The two cones of water above and below the water-wire into which the top and bottom part of the original bridge evolve (see Fig. 1), are also under positive but much smaller Laplace pressure: the external curvatures of the cones are 
zero, while their principal curvatures are positive, even if much smaller than in the water-wire. Most interestingly, at the close neighborhood of the transition perimeters between the water-wire and the cones, the situation is drastically different. The external curvature is negative and locally very high, likely reaching values larger than that of the gorge (wire), hence yielding a negative, localized suction. Such localized high gradients of pressure in the neighborhood of the extremities of the water-wire may easily be viewed as the cause of the observed pinching instability and eventual rupture of the water bridge. Detailed analysis of the pinching instability is presented in a separate paper.

The above-described evolution is consistent with pressures after the rupture: positive $\Delta p$ in the two water semi-drops and in the spherical satellite droplet.

Mode 2 rupture of short and wide bridges (small separations) without formation of the water-wire, exhibits an interesting precursor of rupture as visible in Fig. 8. Such a precursor, observable at time macro-scale, occurs for 0.7 and $0.4 \mathrm{~mm}$ separations about 7 to 10 minutes before the end of evaporation. It consists in an inversion of suction growth into its decrease, or in a change from negative to positive Laplace pressure rate of change. During extension (Fig. 8b) such inversion occurs for all water volumes. However, it does not have any meaning of a precursor. In fact, it may take place at a very initial stage of the process.

With the value of gorge radius and Laplace pressure it is possible to estimate pressure resultant force at the neck level, from the equation $F_{\Delta p}=$ $\pi r_{g}{ }^{2} \Delta p$ (Haines 1925, Lian et al. 1993, Butt and Kappl 2009). The increasing pressure difference several seconds before rupture is moderated by a decreasing surface area of the gorge cross-section and the resulting force $F_{S}$ remains almost constant, and it is always positive (repulsive). Its value increases slightly with the bridge volume.

The second component of the intergranular force is the surface tension force, acting at the bridge perimeter at its neck. The surface tension force $F_{\mathrm{ST}}=2 \pi r_{g} \gamma$ is proportional to the gorge radius and it decreases with time, as presented in Fig. 10a. Its value may be several times higher than the value of the corresponding pressure resulting force, so it is found to play main role during bridge evolution.

Both component forces increase significantly when the final water volume is larger for the evaporation tests, and are almost independent of the critical volume at rupture for the extension tests (with a small increase of final suction force with volume), as presented in Fig. 10.

Total intergranular (capillary) force may be calculated using gorge method, as a sum of these two component forces: $F_{\mathrm{CAP}}=F_{\Delta p}+F_{\mathrm{ST}}$ (Willett 

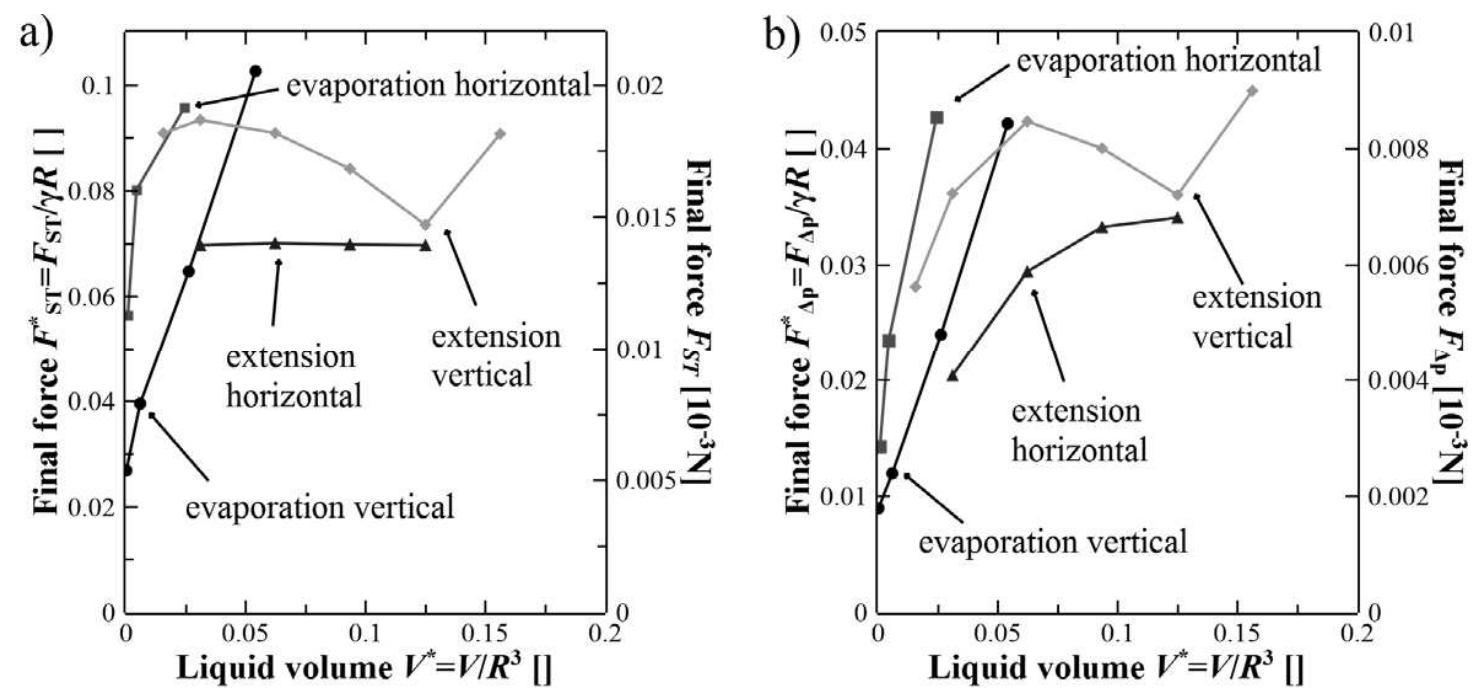

Fig. 10. Final values of surface tension force (a) and Laplace pressure resulting force (b) for evaporation and extension tests. Colour version of this figure is available in electronic edition only.
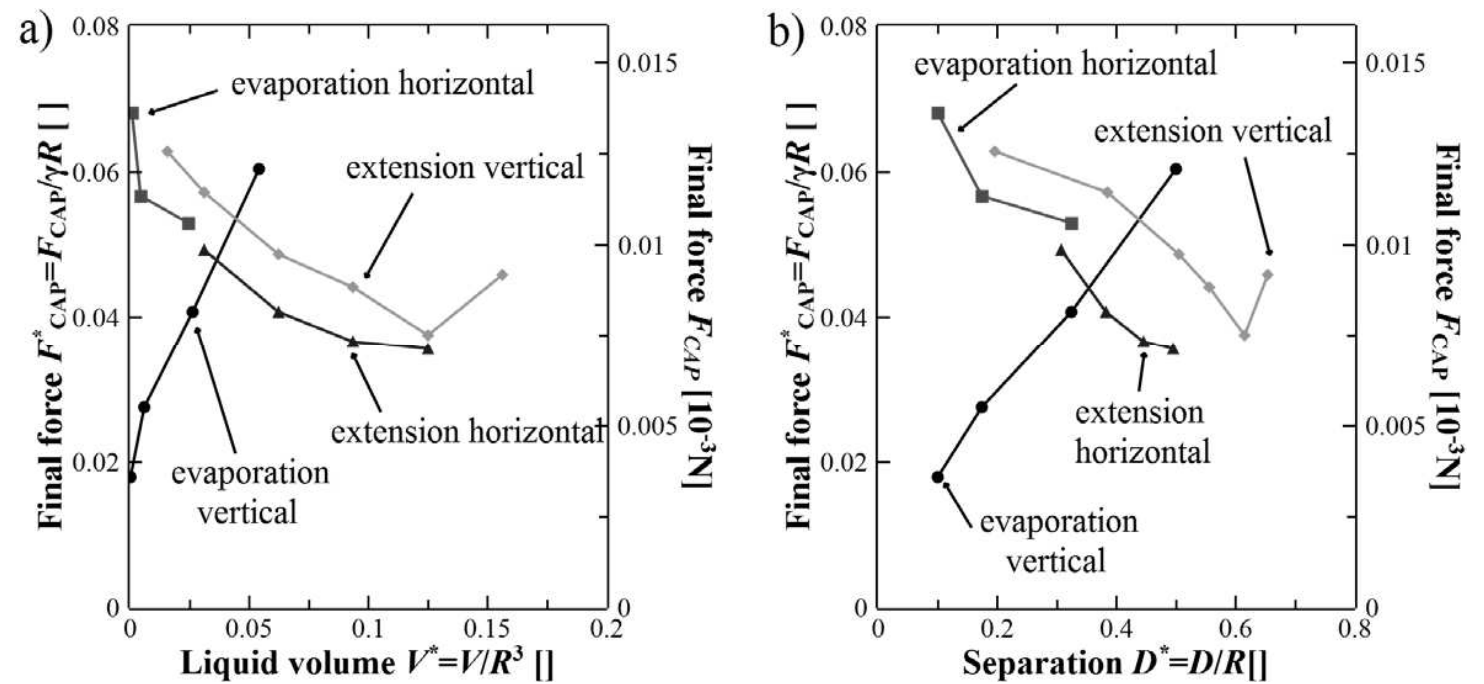

Fig. 11. Final capillary force (capillary force jump) versus critical water volume (a) or critical separation (b) for extension and evaporation tests. Colour version of this figure is available in electronic edition only.

et al. 2000, Lian et al. 1993, Butt and Kappl 2009). The gravity force is ignored here.

During the final stage of both processes, the total intergranular force value decreases, with a jump to zero at the moment of the rupture. The final values of the intergranular force (or force jump) depend on whether the configuration is horizontal or vertical and are different for evaporation and extension, as presented in Fig. 11. The final intergranular force decreases along the increasing final volume and final separation at rupture for all the tests 
and configurations, except for the evaporation of liquid bridge in a vertical arrangement of spheres, when an increase of this force with increasing volume (separation) is observed. The presented results are complementary to the results obtained during the time macro-scale experiments, where decreasing capillary force with decreasing water volume or increasing sphere separation is observed.

\section{DISCUSSION}

The phenomenon of rupture of liquid bodies has been a subject of interest for several decades, with the first detailed record of the moment of rupture presented by Edgerton et al. (1937) in an example of pendant drop breakage. Notably, the changes in the water body shape, and hence the curvatures which control the Laplace pressure and surface tension, undergo instabilities that are observed in both time scales, the time macro-scale of minutes and at the time micro-scale (of milliseconds). For Mode 2 it is clear that these are two different processes, one occurring approximately 7-10 min before the rupture (Fig. 8a), the other one taking a few milliseconds prior to rupture (Fig. 5a and 7a). The latter process qualifies as mechanical Lyapunov instabilities, when infinitesimal solicitations result in an uncontrollably large response. For Mode 1, for high aspect ratio bridges, it is less clear. On time macro-scale the process is seen within the last minute, while at micro-scale the instability takes place within a few last milliseconds, or their fraction.

There are at least three ways of looking at the rupture: as a condition at which basic laws of physics and geometry of the liquid bridge are violated, as instability (bifurcation) of the geometry of the liquid body, or as a local form of fracture or crack of the water body.

Since very early, the physical fact of rupture of liquid bridges was identified with the mathematical concept of loss of existence (or loss of uniqueness) of the solution of the system of coupled equations expressing the minimization of the surface of the liquid bridge. The surface is often of an approximate geometry, fulfilling the Laplace theorem relationship, and constrained by the condition of constant volume (and hence ignoring evaporation) (see, e.g., Haines 1925, Fisher 1926, Erle et al. 1971, Melrose 1966) or/and by constant pressure conditions (Lowry and Steen 1995, de Boer and de Boer 2008, Gras et al. 2013.). As all of these criteria refer to extension tests, they are classically expressed via a critical separation $D_{\text {rup }}$, corresponding to the point of loss of existence of the solution, in this case as approximate closed form formulae, as presented by Lian et al. (1993) and Willett et al. (2000). Experimentally determined critical separations for evaporation and extension are very close to the calculated values for extension (according to Lian and Willett equations) with averaged contact angle (Fig. 4). 
Similar evolution of the water body profile is considered in discussions about a steady-state fluid jet instability, known as Rayleigh-Plateau instability, which would take on forms of alternative geometry (Plateau 1864, van Honschoten et al. 2010). The last stage of the process, beyond a point of instability, is considered as irreversible (Padday et al. 1997). This stage may be broken down into three periods: non-equilibrium Laplace shapes, bridge elongation (with acceleration) and cylindrical neck (water wire) evolution, as proposed by Padday et al. (1997) for pendant bridges. As postulated by Padday et al. (1997) such evolution may be explained by a flow of water from the neck region towards both supporting surfaces. The flow of water is accompanied by a decrease in surface energy.

For higher separations, the mid-section of the bridge evolves into a water-wire, which then breaks in two contact points simultaneously, or at first at lower contact point, and very soon (in about $0.02 \mathrm{~ms}$ ), at the upper contact point. The presence of rupture (and bifurcations) at the both ends of liquid bridge was described also for the break-up of a jet or liquid drop (Peregrine et al. 1990, Eggers 1997), where evolutionary stages of bifurcation, formation of cylindrical neck, breakage and a satellite drop with the double breakage of the neck region were described.

The rupture of the wire in two points simultaneously was observed also during rupture of pendant bridges in simulated low gravity, presented by Padday et al. (1997). In these studies, each phase: bifurcation, breakage, and recoil took place symmetrically, even for extension experiments, with moving upper sphere. Authors suggest that breakage is driven solely by a decrease in surface area of the liquid -fluid interface.

For the smallest pendant bridges, the neck region is stretching and thinning, until it ruptures in the middle. After the rupture, two halves of the bridge relax into semi-spherical cap shapes without visible recoil and wave formation, as reported for experiments with low-gravity environment by Padday (1992), Zhang et al. (1996), Brenner et al. (1994), and Shi et al. (1994). Non-symmetrical rupture was observed by Peregrine et al. (1990) or during experiments with falling drop. They explain that the rupture at the upper contact point may be initiated by propagating wave generated by the first rupture.

Several forces and phenomena may be responsible for the rupture of liquid bridges: Laplace pressure, gravity force, van der Walls forces, extension strain or surface tension of the liquid. All these elements are acting together, but with a different impact and different influence on the liquid body.

According to Eggers (1997), the dynamics near the breakup is not dependent on the particular setup (jet decay, dripping faucet, etc.) but it is a result of the nonlinearities of the equations of motion. As the motion near a location of the breakup gets faster, only fluid very close to that point is 
able to follow, making the breakup localized both in space and time. Thus one expects the motion to become independent of initial conditions, and the type of experiment becomes irrelevant to the study of the singular motion. The observed rupture of the bridge caused by evaporation resembles breakups of a liquid jet, falling droplet or others types of rupture.

Analogously, for the liquid jets Eggers (1997) has shown that the last stages of pinching happen very fast. At the pinch point, the radius of curvature goes to zero, and the small amount of fluid left in the pinch region is driven by increasingly strong forces. Thus, the velocity goes to infinity, and the separation of a drop corresponds to a singularity of the equations of motion, in which the velocity and gradients of the local radius diverge. Even in the case of an infinite-time singularity of the equations of hydrodynamics, the physical event of breaking may occur in finite time. That is, when the fluid thread has become sufficiently thin, it may break owing to the microscopic effects that are outside the realm of hydrodynamics (Eggers 1997).

Liquid wire evolution per se has been also identified with instability or bifurcation of its equilibrium, the alternative form of which would be found via geometrical (sinusoidal) perturbation. So, this is a structural, rather than material instability, see, e.g., Lowry and Steen (1995), Bernoff et al. (1998), Vaynblat et al. (2001), Eggers et al. (1997), Peregrine et al. (1990).

Peregrine et al. (1990) compared the characteristic times related to gravity effects and strain rate with a time of rupture, concluding that larger-scale flow does not play important role at the stage of rupture. Van der Waals forces considered by Vaynblat et al. (2001) in the study of instability of a liquid column via method of perturbation through pinching concluded that for van der Waals forces to become relevant the radii need to be of the order of nanometers (which is by far smaller than ours) and still the contribution of surface tension to instability was insignificant. Peregrine et al. (1990) maintains that in the stage of creation of water-wire surface tension is presumed to dominate the mechanics of the bridge.

In our experiments we find that the pressure inside the bridge is positive (repulsive) just before the rupture. We concluded also that most likely there is significant gradient of pressure at the moment of creation of the water wire, with positive pressure inside the bridge, negative pressure (suction) at contact points, and positive pressure in hemi-spherical parts of water bridge. Such a gradient of pressure (and positive pressure before creation of water wire) could constitute a condition for rupture. But comparing pressure and the resultant surface tension forces (two components of total intergranular force), it may be concluded, that although the positive pressure may disjoin the water body in the thinnest point, surface tension is high enough to counteract. The sum of both resultant forces of pressure and surface tension (total intergranular force) is always attractive before the rupture (Fig. 9). 
Calculated surface tension force is globally attractive, and it is much higher than repulsive Laplace pressure resulting force. But during the evaporation process, liquid bridge loses its volume, and becomes very thin in the middle. There is in important remark concerning all the calculations, based on geometrical parameters: all the variables are calculated at the neck level, in the macro-scale approach. Local values and especially directions of the locally acting forces are likely to vary across the bridge, because of space variability of curvatures.

\section{CONCLUSIONS}

We recorded images of rupture of evaporating liquid bridge between two identical glass spheres using fast camera with over than 27000 images/ second for a series of fixed separations. Rupture of kinematically extended liquid bridges, at constant liquid volume was also recorded in similar conditions for comparison. Based on measured principal radii of curvature at the bridge gorge and a value of surface tension, we calculated Laplace pressure, surface tension resultant force, as well as total intergranular force evolution, for both processes, and for two geometrical configurations: horizontal and vertical arrangement of spheres.

Rupture appears to take two modes. Mode 1, with a water-wire formed and evolving at the center of a bridge, and Mode 2, with water evaporating entirely followed by rupture at the center with a separation of the abutments of the bridge. Mode 1 is characteristic for taller and slender bridges, at large separations, Mode 2 arises in stouter bridges. Taller bridges at large separations develop instability at a significantly earlier stage: at $2 \mathrm{~mm}$ separation the rupture occurs after 9 minutes when only one-fourth of water evaporated. Mode 1 develops in a two stage process: first a Raleigh-Plateau type of instability was observed with a transition from a catenoid form to nodoid. The latter one consisted in development in the central part of the bridge of a cylindrical water-wire defined as that of a constant gorge diameter and zero external (lateral) curvature over a certain length. Formally, the Raleigh instability consists in transition of the mean principal curvature from negative to positive.

The second stage of the process arises within $3 \mathrm{~ms}$ from the original one and consists in pinching of the column either at two extremities of the waterwire simultaneously, or first at the bottom followed by a second pinch at the top. Pinching instability is a well-developed concept in fluid mechanics (Vaynblat et al. 2001). It is observed that at the moment of pinching there is a substantial singularity of Laplace pressure calculated from the principal curvatures of the body of water consisting of two conical abutments of the bridge and a cylindrical water-wire in the middle. Based on the curvatures, there is a positive pressure in the water-wire and much less in the cones. 
However, in the isolated point (circle in 3D) of transition between the waterwire and the cone there is a competition between positive contribution from the gorge curvature and negative contribution of the principal external (lateral) curvature at the cone-column corner. This competition leads to a highly variable singularity of Laplace pressure that likely can reach localized negative values (suction).

Acknowledgments. The authors acknowledge the partial support of US NSF grant No. 0700294 of CMMI Division, Geomechanics and Geomaterials Program (T. Hueckel) and support of MIST Laboratory (IRSNCNRS-UM2) and the Languedoc-Roussillon region (B. Mielniczuk, M.S. El Youssoufi, T. Hueckel).

\section{References}

Bernoff, A.J., A.L. Bertozzi, and T.P. Witelski (1998), Axisymmetric surface diffusion: dynamics and stability of self-similar pinchoff, J. Stat. Phys. 93, 3-4, 725-776, DOI: 10.1023/B:JOSS.0000033251.81126.af.

Bièvre, G., D. Jongmans, T. Winiarski, and V. Zumbo (2012), Application of geophysical measurements for assessing the role of fissures in water infiltration within a clay landslide (Trièves area, French Alps), Hydrol. Process. 26, 14, 2128-2142, DOI: 10.1002/hyp.7986.

Brenner, M.P., X.D. Shi, and S.R. Nagel (1994), Iterated instabilities during droplet fission, Phys. Rev. Lett. 73, 25, 3391-3396, DOI: 10.1103/PhysRevLett. 73.3391.

Bush, J.W.M. (2004), MIT Lecture Notes on Surface Tension, Sect. 5, Massachusetts Institute of Technology, Cambridge, pdf.

Butt, H.-J., and M. Kappl (2009), Normal capillary forces, Adv. Coll. Interf. Sci. 146, 1-2, 48-60, DOI: 10.1016/j.cis.2008.10.002.

De Bisschop, F.R.E., and W.J.L. Rigole (1982), A physical model for liquid capillary bridges between adsorptive solid spheres: The nodoid of plateau, J. Coll. Interf. Sci. 88, 1, 117-128, DOI: 10.1016/0021-9797(82)90161-8.

de Boer, P.C.T., and M.P. de Boer (2008), Rupture work of pendular bridges, Langmuir 24, 1, 160-169, DOI: 10.1021/la701253u.

Dixon, D., N. Chandler, J. Graham, and M.N. Gray (2002), Two large-scale sealing tests conducted at Atomic Energy of Canada's underground research laboratory: the buffer-container experiment and the isothermal test, Can. Geotech. J. 39, 3, 503-518, DOI: 10.1139/t02-012. 
Edgerton, H.E., E.A. Hauser, and W.B. Tucker (1937), Studies in drop formation as revealed by the high-speed motion camera, J. Phys. Chem. 41, 7, 10171028, DOI: $10.1021 / \mathrm{j} 150385 \mathrm{a} 012$.

Eggers, J. (1997), Nonlinear dynamics and breakup of free-surface flows, Rev. Mod. Phys. 69, 3, 865-929, DOI: 10.1103/RevModPhys.69.865.

Erle, M.A., D.C. Dyson, and N.R. Morrow (1971), Liquid bridges between cylinders, in a torus, and between spheres, AIChE J. 17, 1, 115-121, DOI: 10.1002/aic.690170125.

Fisher, R.A. (1926), On the capillarity forces in an ideal soil; correction of formulae given by W.B. Haines, J. Agric. Sci. 16, 3, 492-505, DOI: 10.1017/ S0021859600007838.

Gili, J.A., and E.E. Alonso (2002), Microstructural deformation mechanisms of unsaturated granular soils, Int. J. Numer. Anal. Meth. Geomech. 26, 5, 433468, DOI: 10.1002/nag.206.

Gras, J.-P., J.-Y. Delenne, and M.S. El Youssoufi (2013), Study of capillary interaction between two grains: a new experimental device with suction control, Granul. Matter 15, 1, 49-56, DOI: 10.1007/s10035-012-0388-2.

Haines, W.B. (1925), Studies in the physical properties of soils: II. A note on the cohesion developed by capillary forces in an ideal soil, J. Agric. Sci. 15, 4, 529-535, DOI: $10.1017 /$ S0021859600082460.

Hoek, E., and J.W. Bray (1981), Rock Slope Engineering, 3rd ed., CRC Press, London.

Hu, L.B., H. Péron, T. Hueckel, and L. Laloui (2007), Drying shrinkage of deformable porous media: mechanisms induced by the fluid removal. In: T.C. Siegel et al. (eds.), Proc. GeoDenver 2007 "Computer Applications in Geotechnical Engineering”, 18-21 February 2007, Denver, USA, GSP No. 157, DOI: 10.1061/40901(220)17.

Hu, L.B., H. Peron, L. Laloui, and T. Hueckel (2011), A multi-scale multi-physics model of soil drying. In: Proc. Geo-Frontiers 2011 "Advances in Geotechnical Engineering”, 13-16 March 2011, Dallas, USA, ASCE GSP No. 211, 4349-4358, DOI: 10.1061/41165(397)445.

Hu, L.B., H. Péron, T. Hueckel, and L. Laloui (2013a), Desiccation shrinkage of non-clayey soils: multiphysics mechanisms and a microstructural model, Int. J. Numer. Anal. Meth. Geomech. 37, 12, 1761-1781, DOI: 10.1002/nag.2108.

Hu, L.B., H. Péron, T. Hueckel, and L. Laloui (2013b), Desiccation shrinkage of non-clayey soils: a numerical study, Int. J. Numer. Anal. Meth. Geomech. 37, 12, 1782-1800, DOI: 10.1002/nag.2107.

Hueckel, T., B. Mielniczuk, and M.S. El Youssoufi (2013), Micro-scale study of rupture in desiccating granular media. In: C. Meehan et al. (eds.), Proc. Geo-Congress 2013 "Stability and Performance of Slopes and Embankments III", 3-7 March 2013, San Diego, USA, ASCE GSP No. 231, 808817, DOI: $10.1061 / 9780784412787.082$. 
Hueckel, T., B. Mielniczuk, M.S. El Youssoufi, L.B. Hu, and L. Laloui (2014), A three-scale cracking criterion for drying soils, Acta Geophys. 62, 5, DOI: 10.2478/s11600-014-0214-9 (this issue).

Kowalski, S.J., and B. Mielniczuk (2007), Analysis of effectiveness and stress development during convective and microwave drying, Dry. Technol. 26, 1, 64-77, DOI: $10.1080 / / 07373930701781637$.

Lautrup, B. (2011), Physics of Continuous Matter. Exotic and Everyday Phenomena in the Macroscopic World, 2nd ed., CRC Press, Boca Raton, 696 pp.

Leppinen, D., and J.R. Lister (2003), Capillary pinch-off in inviscid fluids, Phys. Fluids 15, 2, 568-578, DOI: 10.1063/1.1537237.

Lian, G., C. Thornton, and M.J. Adams (1993), A theoretical study of the liquid bridge forces between two rigid spherical bodies, J. Colloid Interf. Sci. 161, 1, 138-147, DOI: 10.1006/jcis.1993.1452.

Lowry, B.J., and P.H. Steen (1995), Flow-influenced stabilization of liquid columns, J. Colloid Interf. Sci. 170, 1, 38-43, DOI: 10.1006/jcis.1995.1068.

Maeda, N., J.N. Israelachvili, and M.M. Kohonen (2003), Evaporation and instabilities of microscopic capillary bridges, Proc. Natl. Acad. Sci. USA 100, 3, 803-808, DOI: 10.1073/pnas.0234283100.

Mason, G., and W.C. Clark (1965), Liquid bridges between spheres, Chem. Eng. Sci. 20, 10, 859-866, DOI: 10.1016/0009-2509(65)80082-3.

Mazzone, D.N., G.I. Tardos, and R. Pfeffer (1986), The effect of gravity on the shape and strength of a liquid bridge between two spheres, J. Colloid Interf. Sci. 113, 2, 544-556, DOI: 10.1016/0021-9797(86)90187-6.

Melrose, J.C. (1966), Model calculations for capillary condensation, AIChE J. 12, 5, 986-994, DOI: 10.1002/aic.690120526.

Mielniczuk, B., T. Hueckel, and M.S. El Youssoufi (2014), Evaporation-induced evolution of the capillary force between two grains, Granul. Matter, DOI: 10.1007/s10035-014-0512-6.

Padday, J.F. (1963), Heights of sessile drops and meniscus properties, Nature 198, 4878, 378-379, DOI: 10.1038/198378a0.

Padday, J.F. (1992), The formation and breakage of liquid bridges under microgravity, Microgravity Q. 2, 4, 239-249.

Padday, J.F., G. Pétré, C.G. Rusu, J. Gamero, and G. Wozniak (1997), The shape, stability and breakage of pendant liquid bridges, J. Fluid Mech. 352, 177204, DOI: 10.1017/S0022112097007234.

Peregrine, D.H., G. Shoker, and A. Symon (1990), The bifurcation of liquid bridges, J. Fluid Mech. 212, 25-39, DOI: 10.1017/S0022112090001835.

Péron, H., J.Y. Delenne, L. Laloui, and M.S. El Youssoufi (2009a), Discrete element modelling of drying shrinkage and cracking of soils, Comput. Geotech. 36, 1-2, 61-69, DOI: 10.1016/j.compgeo.2008.04.002.

Péron, H., T. Hueckel, L. Laloui, and L.B. Hu (2009b), Fundamentals of desiccation cracking of fine-grained soils: experimental characterization and mecha- 
nisms identification, Can. Geotech. J. 46, 10, 1177-1201, DOI: 10.1139/ T09-054.

Péron, H., L. Laloui, L.B. Hu, and T. Hueckel (2013), Formation of drying crack patterns in soils: a deterministic approach, Acta Geotech. 8, 2, 215-221, DOI: $10.1007 / \mathrm{s} 11440-012-0184-5$.

Plateau, J. (1864), The figures of equilibrium of a liquid mass, The Annual Report of the Smithsonian Institution, Washington DC, USA, 338-369.

Plateau, J. (1873), Statique Expérimentale et Théorique des Liquides Soumis aux Seules Forces Moléculaires, Gauthier-Villars, Paris (in French).

Shi, X.D., M.P. Brenner, and S.R. Nagel (1994), A cascade of stucture in a drop falling from a faucet, Science 265, 5169, 219-222, DOI: 10.1126/science. 265.5169.219.

van Honschoten, J.W., N.R. Tas, and M. Elwenspoek (2010), The profile of a capillary liquid bridge between solid surfaces, Am. J. Phys. 78, 3, 277-286, DOI: 10.1119/1.3273854.

Vaynblat, D., J.R. Lister, and T.P. Witelski (2001), Rupture of thin viscous films by van der Waals forces: Evolution and self-similarity, Phys. Fluids 13, 5, 1130-1140, DOI: 10.1063/1.1359749.

Willett, Ch.D., M.J. Adams, S.A. Johnson, and J.P.K. Seville (2000), Capillary bridges between two spherical bodies, Langmuir 16, 24, 9396-9405, DOI: 10.1021/la000657y.

Zhang, X., R.S. Padgett, and O.A. Basaran (1996), Nonlinear deformation and breakup of stretching liquid bridges, J. Fluid Mech. 329, 207-245, DOI: $10.1017 / \mathrm{S} 0022112096008907$. 